\title{
Instituições do Estado desenvolvimentista na América Latina no contexto pós- neoliberal: os casos do Brasil e Argentina em perspectiva comparada.
}

\author{
Moisés Villamil Balestro \\ Universidade de Brasília
}

\section{Resumo}

$O$ artigo analisa características do Estado desenvolvimentista no período pós-neoliberal no Brasil e na Argentina. A emergência de uma fase pós-neoliberal na América Latina está associada, ainda que sob diferentes matizes ideológicas, à ideia de expansão de políticas sociais e à retomada do papel do Estado na formulação $e$ incentivo a estratégias de desenvolvimento econômico. Um aspecto fundamental para a eficácia das estratégias de desenvolvimento são as instituições e organizações envolvidas politica e economicamente. Como mostra a literatura, o desafio de construir um Estado desenvolvimentista requer a combinação de um Estado facilitador com uma estratégia de upgrading industrial acompanhada de aumento da inclusão social. Uma diferença relevante no caso brasileiro em relação ao caso argentino foi a permanência de instituições que foram construídas durante o período desenvolvimentista, com especial destaque para o BNDES.
Ao verificar a relação entre Estado $e$ desenvolvimento nos dois países, foi possível identificar quatro diferenças fundamentais do Brasil em relação à Argentina; uma forte instituição financeira de desenvolvimento $e$ instituições financeiras públicas, uma maior capacidade estatal com uma burocracia estável e meritocrática no caso brasileiro, políticas sociais de longo prazo e uma relação mais cooperativa entre Estado $e$ empresariado.

Palavras-chave: Instituições, Estado desenvolvimentista, Brasil, Argentina

\begin{abstract}
The paper analyzes traits of developmental state in the post-neoliberal era in Brazil and Argentina. The emergence of a postneoliberal era in Latin America is associated, under different ideological shades, to the strengthening of social policies and to the resurge of the state in the design and incentives to foster economic development strategies. Institutions and organizations
\end{abstract}


politically and economically committed are a fundamental tenet for the efficacy of development strategies. As of literature, the challenge of building a developmental state requires the combination of an enabling state carrying out a industrial upgrading strategy together with greater social inclusion. A relevant difference in the Brazilian case towards the Argentinian was the survival of developmentalist institutions from early industrialization period with a special emphasis for BNDES. By verifying the relationship between state and development in both countries, it was possible to identify four major differences between Brazil and Argentina: a strong financial development institution and strong public financial institutions, a greater state capacity with a stable and meritocratic bureaucracy in Brazil, long term social policies and a more cooperative relationship between business and the state.

Keywords: developmental state, Brazil, Argentina, Institutions.

\section{Introdução}

A emergência de uma fase pósneoliberal na América Latina está associada, ainda que sob diferentes matizes ideológicas, à ideia de expansão de políticas sociais e à retomada do papel do Estado na formulação e incentivo a estratégias de crescimento econômico. Após as experiências da construção do Estado no período de substituição de importações com seu respectivo esgotamento com as agudas crises dos anos 80, iniciam-se reformas de fortalecimento dos mercados, políticas de estabilização e criação de regras do jogo para garantir a democracia liberal

Um aspecto fundamental para a eficácia das estratégias de desenvolvimento são as instituições e organizações envolvidas política e economicamente (Riain, 2004). A estratégia desenvolvimentista está imbricada em diferentes formas de instituições desenvolvimentistas. Como lembram Lange e Rueschemeyer (2005), quaisquer que sejam as políticas desejadas, elas precisam estar no âmbito das capacidades do Estado de um dado país. Isso indica que o reconhecimento do papel do Estado deve ser consonante com a trajetória de cada país para uma ação mais eficaz deste Estado.

$\mathrm{Na}$ literatura sobre estado desenvolvimentista, a ênfase na formação de uma racionalidade burocrática é necessária, mas não suficiente para o developmental 
state. A regra burocrática é consistente com as rivalidades intragovernamentais e disputas para obtenção dos recursos (Chibber, 2002). Desta forma, a racionalidade burocrática precisa estar acompanhada da coesão estatal e isso é garantido por meio um esforço de coordenação do aparato estatal. Os conflitos entre agências surgem em função da complexa amálgama de agências responsabilizadas com distintas funções e cujos papéis são frequentemente sombreados, além da competição por recursos. Conforme Portes e Smith (2010), uma combinação chave em uma instituição desenvolvimentista é a combinação de algumas medidas de qualidade interna com o envolvimento ativo dos atores estratégicos, empresariado e trabalhadores. Este último parece ser o mais problemático no contexto latinoamericano. Há uma tendência ora ao insulamento da burocracia ora a captura do Estado por grupos privados, não conseguindo envolver outros atores chaves.

Neste sentido, vale o exercício de entender a relação entre o Estado, suas instituições e desenvolvimento no Brasil e na Argentina como elemento explicativo do desempenho econômico destes países no período pós-neoliberal.

Em que pese a especificidade histórica do peronismo, capaz de abrigar ao mesmo tempo o mais ortodoxo representante do neoliberalismo na América Latina e os representantes mais críticos da experiência neoliberal no cone sul, o discurso oficial dos últimos governos na Argentina têm sinalizado uma escolha em favor de ideias e políticas que se aproximam da social-democracia. Em contraste, o discurso do Governo Lula foi bastante moderado em relação a mudanças na política econômica. Somente quando os sinais de desindustrialização se tornam alarmantes, tem início um processo lento e gradual de redução nos juros que ganha consistência no atual Governo Dilma.

No entanto, para além dos discursos e das mudanças nas políticas econômicas, é necessário considerar quais instituições podem ser chaves na construção de um Estado desenvolvimentista nos casos argentino e brasileiro. O caso brasileiro possui uma coincidência entre uma legislação de proteção social na saúde e educação a partir da Constituição de 1988 e o início de políticas neoliberais alguns anos mais tarde. Em políticas sociais, há o Sistema Único de Saúde, a proteção social na forma de segurodesemprego, a manutenção de uma previdência pública e a expansão, ainda que com a queda na qualidade, da educação pública universal. Os governos e políticas de orientação neoliberal não foram capazes de fazer retroceder tais conquistas.

No caso argentino, houve severo retrocesso nas políticas sociais. Os programas universais de saúde pública foram 
descentralizados para as províncias sem haver a devida compensação em termos tributários. O sistema previdenciário foi parcialmente privatizado e os investimentos em educação pública foram reduzidos. A desarticulação do setor produtivo contribuiu para o agravamento desta situação com trabalhadores desempregados exercendo maior pressão sobre o atendimento público de saúde. O período neoliberal foi ainda mais deletério para a indústria do que no caso brasileiro. Segundo Ferrer (2008), a taxa de acumulação de capital da economia argentina caiu de $22 \%$ entre 1930 e 1975 para 15\% no período neoliberal. A participação da indústria manufatureira no PIB do país caiu de $33 \%$ para $16 \%$ no período entre 1976 e 2001.

A fim de entender conceitualmente as instituições do Estado desenvolvimentista no contexto latino-americano, o artigo está organizado em cinco partes. A primeira apresenta alguns apontamentos sobre a relação entre Estado e desenvolvimento. A segunda e terceira partes trazem apontamentos da relação entre Estado e desenvolvimento na Argentina e no Brasil. A seguir, são feitas comparações de dados agregados do desempenho econômico brasileiro e argentino. Ao final, são tecidas considerações e aspectos a serem investigados como pesquisa futura.

\section{Estado e desenvolvimento}

O primeiro suposto da relação entre Estado e desenvolvimento tem a ver com a ação do Estado e o desenvolvimento capitalista bem sucedido. Esta ação pode assumir as formas de intervenção, regulação ou indução. O papel do Estado torna-se mais claro ao relacioná-lo com a acumulação de capital, ao invés de tratar Estado e mercado de forma dicotômica. A política do Estado afeta as formas e o ritmo de acumulação de capital. Nitidamente, o Estado controlado por elites identificadas com um modelo agro-exportador tende a privilegiar grandes grupos econômicos vinculados à produção de commodities em detrimento do estímulo e apoio aos setores industriais nascentes com maior densidade tecnológica. No contexto latinoamericano, é clara a distinção entre apoiar as elites empresariais relacionadas com o lucro que advém de maior eficiência econômica nos fatores de produção capital, trabalho e tecnologia e apoiar as elites identificadas com o rentismo que buscam a segurança do Estado para garantir oportunidades de renda. As oportunidades de renda são variadas; monopólios privados protegidos pelo Estado, protecionismo a setores ineficientes, empresas que se organizam de forma clientelista em torno dos investimentos públicos entre outros.

$\mathrm{Na}$ relação entre Estado e desenvolvimento, é essencial olhar para dentro desta instituição. Trata-se de vê-lo 
como um ator corporativo não-monolítico. Neste sentido, a literatura sobre Estado desenvolvimentista ao longo de quase trinta anos tem enfatizado aspectos essenciais como a formação, a racionalidade e coesão da burocracia e o imbricamento desta com as elites empresariais que impulsionam uma acumulação de capital baseada no lucro e não na renda.

Há dois elementos institucionais nãoformais chaves para o funcionamento desta burocracia. O primeiro tem a ver com o processo de socialização desta burocracia por meio da partilha de uma linguagem comum, de um ethos e de um entendimento minimamente comum em relação ao papel do Estado na sociedade. O segundo elemento diz respeito ao papel da liderança que se expressa em um comprometimento da alta cúpula do governo e uma espécie de dominação carismática em relação a essa burocracia. É o que Skocpol (1985) chama de elementos não- burocráticos do funcionamento burocrático.

Como toda instituição inserida em uma dinâmica societal, o Estado possui dependência de trajetória. A relação entre Estado e desenvolvimento econômico é uma relação de longo prazo. Os efeitos destas instituições de longo prazo tendem a persistir durante longos períodos históricos. A instabilidade política, as influências das elites rentistas e as dificuldades de coordenação entre os atores em torno de uma estratégia de desenvolvimento constituem exemplos destes efeitos de longo prazo. Uma questão essencial é entender como determinados incentivos e interesses avessos a uma estratégia desenvolvimentista se reproduzem. Neste sentido, um desafio para a retomada do Estado desenvolvimentista em uma sociedade complexa é encontrar as condições sob as quais os efeitos negativos de longo prazo podem ser superados. 
Quadro 1 - Fatores que retardam o desenvolvimento do Estado

\begin{tabular}{|c|c|c|}
\hline & $\begin{array}{c}\text { Mudança institucional e } \\
\text { normativa }\end{array}$ & Conflitos e impasses \\
\hline \multirow{5}{*}{ Dentro do Estado } & $\begin{array}{c}\text { Tensões entre lealdade } \\
\text { baseada em laços pessoais } \\
\text { e vantagens individuais e } \\
\text { lealdade baseada em } \\
\text { comprometimento pessoal } \\
\text { e meritocracia. }\end{array}$ & $\begin{array}{l}\text { Funcionários buscam consolidar } \\
\text { ganhos privados buscando } \\
\text { direitos proprietários e } \\
\text { hereditários contra o interesse } \\
\text { no centro no controle }\end{array}$ \\
\hline & $\begin{array}{l}\text { Construção de instituição } \\
\text { de longo prazo exige } \\
\text { recursos culturais, políticos } \\
\text { e econômicos e pode ser } \\
\text { descontinuada ou falhar. }\end{array}$ & $\begin{array}{l}\text { Oposição persistente de } \\
\text { funcionários estimulados por } \\
\text { interesses externos, lealdades e } \\
\text { orientações culturais. }\end{array}$ \\
\hline & $\begin{array}{c}\text { A institucionalização de } \\
\text { normas e sua internalização } \\
\text { leva tempo. }\end{array}$ & $\begin{array}{c}\text { Reestruturar as organizações } \\
\text { administrativas e reorientar a } \\
\text { política pública contra a } \\
\text { resistência de um grupo coeso } \\
\text { pode levar a conflitos repetidos. }\end{array}$ \\
\hline & $\begin{array}{l}\text { Normas do padrão mais } \\
\text { eficaz são lentas em sua } \\
\text { aceitação e adoção }\end{array}$ & \multirow{2}{*}{$\begin{array}{l}\text { Conflitos podem surgir da } \\
\text { antinomia entre questões } \\
\text { inerentemente não-burocráticas } \\
\text { de orientação política e lógica } \\
\text { instrumental da administração }\end{array}$} \\
\hline & $\begin{array}{c}\text { Um grupo coeso para } \\
\text { monitorar e controlar o } \\
\text { comportamento de acordo } \\
\text { com normas internalizadas } \\
\text { leva tempo para se formar }\end{array}$ & \\
\hline \multirow{3}{*}{$\begin{array}{l}\text { Relações Estado e } \\
\text { sociedade }\end{array}$} & $\begin{array}{l}\text { A mudança normativa } \\
\text { pode ocorrer primeiro em } \\
\text { certas instituições e grupos } \\
\text { limitados com status e } \\
\text { interesses partilhados }\end{array}$ & $\begin{array}{l}\text { Governantes tendem a perseguir } \\
\text { objetivos de eficiência com } \\
\text { cautela em função da natureza } \\
\text { contraditória dos interesses das } \\
\text { suas alianças. }\end{array}$ \\
\hline & $\begin{array}{l}\text { A mudança das relações } \\
\text { clientelistas para relações } \\
\text { baseadas em contrato e do } \\
\text { tipo organizacional tende a } \\
\text { ser lenta e desigual. }\end{array}$ & $\begin{array}{l}\text { Conflitos repetidos com atores } \\
\text { que se opõem à perda de poder, } \\
\text { recursos econômicos, as } \\
\text { condições pacíficas do conflito e } \\
\text { a autonomia cultural diminuem } \\
\text { a imposição da regra do Estado. }\end{array}$ \\
\hline & $\begin{array}{l}\text { A difusão de uma } \\
\text { concepção de cidadania } \\
\text { exigente e responsiva em } \\
\text { substituição às relações } \\
\text { baseadas na obediência } \\
\text { tende a ser lenta e } \\
\text { interrompida. }\end{array}$ & $\begin{array}{l}\text { Transformar uma pacificação } \\
\text { eventual em uma paz interna } \\
\text { pela via legal leva tempo e } \\
\text { requer várias adaptações. }\end{array}$ \\
\hline
\end{tabular}

Fonte: Rueschemeyer (2005). 
Ao apresentar as mudanças e tensões que retardam o desenvolvimento do Estado, Rueschemeyer (2005) permite entender melhor a complexidade da construção das instituições do desenvolvimento e dos processos políticos capazes de gerar mudança institucional. Lembrando Riain (2004), uma condição para estratégias de desenvolvimento eficazes é um conjunto economicamente e politicamente sustentável de instituições.

A construção do Estado é algo difícil e de longo prazo, assim como o desenvolvimento de uma relação produtiva entre Estado e sociedade. Quaisquer que sejam as políticas de desenvolvimento desejadas, elas precisam estar, de forma realista, em congruência com as capacidades estatais existentes (Rueschemeyer, 2005). Esta é uma lição chave da visão do Estado em uma perspectiva histórica. Por esta razão, partir das instituições existentes e transformálas mostra-se um caminho mais promissor.

\section{Estado e desenvolvimento na Argentina}

O nacional-desenvolvimentismo argentino não logrou a mesma adesão do empresariado privado como no contexto brasileiro. $\mathrm{O}$ projeto nacional de desenvolvimento peronista foi marcado por conflitos de maior intensidade com as elites agropecuárias e um empresariado industrial mais fraco do que o brasileiro. Apesar de avançar na construção de uma cidadania constituída por trabalhadores sindicalizados e classes médias que se mobilizaram em prol de direitos econômicos e de inclusão social, o peronismo não foi capaz de construir consenso em torno dos princípios do desenvolvimento nacional como o fizera Getúlio Vargas.

Apesar de os governos subseqüentes de Arturo Frondizi (1958-1962) e Arturo Ilia (1963-1966) terem continuado o desenvolvimentismo peronista, a instabilidade política e as dificuldades crescentes com a substituição de importações nos anos 60 e 70 geraram ciclos voláteis de crescimento com recessão e desvalorização da moeda. Nos anos 70, o projeto nacional-desenvolvimentista e a própria ideia do papel indutor do Estado na economia perdera apoio político das elites. Diferentemente do caso brasileiro, em que o Estado conseguiu continuidade em muitas instituições do nacional-desenvolvimentismo tais como as grandes empresas estatais, o BNDE, os bancos públicos e as organizações ligadas ao desenvolvimento científico e tecnológico do país (CNPQ e CAPES).

Uma diferença em relação ao Brasil na formação do Estado argentino no período pósguerra é marcada pela ausência de continuidade de instituições capazes de consolidar políticas ou estratégias de desenvolvimento de longo prazo. A instabilidade política argentina também se revelou maior do que no caso brasileiro, em que pese maior capacidade de organização 
dos trabalhadores e um corporativismo mais consolidado do que no caso brasileiro. Entre 1945 e 1979, a Argentina teve apenas dois anos de período democrático em contraste com o caso brasileiro que teve um período democrático, ainda que com variações em sua intensidade, de dezoito anos (Segura-Ubiergo, 2007).

A ausência de uma capacidade estatal mais avançada, no sentido weberiano, permitiu uma privatização menos regulada do que no Brasil. Isso também permitiu uma enorme centralização do poder de Estado em torno do Ministério da Economia durante o governo Menem. A concentração de poder neste Ministério implicou a retirada de recursos e capacidade de formulação de políticas públicas de outros ministérios. Uma das implicações diretas do processo de centralização de poder no Estado argentino foi a redução do número de funcionários públicos em dois terços no período de 1990 a 1997.

Tal como no caso brasileiro, as reformas do Estado argentino, sob a égide de um gerencialismo que não abriu mão da herança patrimonialista e clientelista, visaram à descentralização das políticas de bem estar social para nível provincial e municipal (Nicola, 2004). A descentralização aumentou as tensões entre governos provinciais e governo federal em torno das questões tributárias. A fragilidade financeira das províncias também abriu espaço para relações de barganha e de caráter clientelista entre o governo federal e as províncias. Isso porque, a partir de um pacto fiscal de 1993, as transferências financeiras federais tornam-se discricionárias, permitindo um maior poder de barganha do governo federal em troca de apoio político. A descentralização não foi acompanhada dos recursos financeiros $\mathrm{e}$ organizacionais para a efetiva gestão das políticas públicas (Nicola, 2004).

Os cortes massivos nos gastos públicos, durante os anos 90, contribuíram para a perda de legitimidade do Estado na sociedade civil. A corrupção associada ao forte desinvestimento em políticas públicas em educação, saúde, habitação minou a hegemonia política do discurso neoliberal e a relação entre as classes trabalhadoras e o peronismo. Entre 1980 e 1995, o percentual da população abaixo da linha de pobreza aumentou de $11,5 \%$ para $25,8 \%$ e, em 2000 , quase um terço da população era pobre (Grugel et Riggirozzi, 2007). De forma bastante mais intensa do que no caso brasileiro, a sociedade argentina teve sua crença minada no caminho à prosperidade pelo fundamentalismo de mercado. Tal situação foi fundamental para explicar o contexto da ascensão de Kirchner com um discurso de veemente condenação das políticas conduzidas durante os anos 90 .

A reforma do Estado no contexto argentino não logrou seu objetivo precípuo de uma maior profissionalização da burocracia. 
Não houve continuidade e consistência da implementação das medidas tanto pela falta de incentivos políticos do governo quanto pela fraqueza institucional associada a uma incapacidade burocrática. As agências governamentais são vistas como corruptas e ineficazes. O Estado argentino inicia o século XXI com problemas estruturais relacionados à capacidade fiscal, às reformas no judiciário e à administração pública no nível provincial.

Comparado com o Estado brasileiro, a escala de weberianismo desenvolvida por Rauch e Evans (1999) é bem menor para o Estado argentino, 3,8 em relação a 7,6 do Brasil. A escala de weberianismo contém itens relacionados com a capacidade estatal, tais como, capacidade de formulação de políticas públicas, ingresso por concurso público, tempo de permanência em cada órgão, nível salarial, egressos de universidades de elite que entram no serviço público entre outros.

A capacidade organizacional fraca também se revela nas associações empresariais como o caso da CEA que não possui recursos e pessoal para o trabalho de coordenação dos interesses empresariais de diferentes setores. A Sociedad Rural Argentina (SRA) possui maior capacidade de ação coletiva. No período de 1955 a 1983, a SRA indicou 94 cargos no governo federal (Schneider, 2004). As clivagens e politização dos conflitos entre os grandes grupos econômicos, os exportadores agrícolas e as pequenas e médias empresas em torno do peronismo criaram dificuldades para coalizões entre o Estado e o empresariado nacional. Mesmo nos períodos em que o governo conseguiu estabelecer mecanismos de consulta com o empresariado, eles não foram duradouros o suficiente para terminar a fragmentação (Schneider, 2004).

Ao contrário de uma situação em que os ganhos associativos estivessem claros para as empresas, prevalecia uma situação em que as empresas tinham pouco a perder em termos de incentivo seletivo de abandonassem as organizações associativas.

Ao contrário da experiência nacionaldesenvolvimentista brasileira em que havia uma ação de fortalecimento dos atores corporativistas, o caso argentino foi mais caótico com apoios erráticos de acordo com circunstâncias muito conjunturais. Os atores estatais claramente beneficiavam uma ou outra associação de acordo com barganhas em torno do apoio ao governo do período.

O resultado é que as associações empresariais argentinas dos anos 90 figuraram entre as mais fracas e fragmentadas da América Latina (Schneider, 2004). Sem uma representação geral da indústria e carentes de recursos organizacionais. $\mathrm{Na}$ relação entre Estado e empresariado, é fato que o último tem um papel relevante no apoio ao surgimento de associações empresariais fortes.

No âmbito das políticas sociais, a intensa desindustrialização e precarização do 
emprego durante o período neoliberal não neutralizou efeitos positivos das políticas sociais compensatórias. Um outro aspecto foi a regressão distributiva que acaba reduzindo a poupança e a taxa de acumulação de capital ao contrair o mercado interno, o emprego e a renda fiscal.

Barbeito e Goldberg (2007) indicam as principais fraquezas e problemas concernentes às políticas sociais argentinas.

Seguro-Desemprego: a natureza das contribuições e a situação de trabalho precário levou a um baixo nível de cobertura, em torno de $5 \%$ a $7 \%$. Esse nível de cobertura contrasta com o caso brasileiro, com de $33 \%$ de cobertura no início dos anos 2000.

Programas de emprego temporário: foram implementados em escala reduzida e com pouco eficiência, sem agências de emprego geograficamente distribuídas. Isso também contrasta com o Brasil quando se considera a capilaridade da rede de postos SINE em todos os estados, capitais e cidades de grande porte.

Programas de promoção de emprego: o programa focou essencialmente em isenções de contribuições de seguridade social e outras incentivos tributários. Controles fracos sobre as empresas beneficiárias do programa pode ter levado à substituição e rotação de trabalhadores.

"Programa Jefes de Hogar": o programa funcionou bem como uma rede de proteção social mínima, em casos de crise social aguda. Limites deste programa são a falta de conexão com políticas ativas de emprego para capacitação e intermediação de mão-de-obra e um benefício fixo independentemente do número de filhos, o que limita seu efeito como política emergencial de combate à pobreza.

Em que pese a existência destas limitações, é necessário apontar uma clara mudança de direção em relação a políticas sociais no país além do aumento da massa salarial. O salário médio do setor privado argentino variou de 1.295 pesos em 2005 para 2.453 pesos em 2008 (Madoery, 2011). O aumento do emprego formal privado entre 1996 e 2008 foi de 67\%. Todavia, a variação do emprego formal na indústria manufatureira foi de 59\%. A maior variação ocorreu na construção civil com aumento de $235 \%$ (Madoery, 2011).

Corroborando o argumento apresentado neste trabalho em relação às capacidades estatais, Madoery (2011) tece recomendações diretamente associadas ao state-building na Argentina. Tais recomendações apontam para o fortalecimento das capacidades estatais centrais de formulação de políticas e leis, a melhora da conexão da política de emprego com o projeto de desenvolvimento nacional e maior institucionalização das políticas, amparando-as em leis e estruturas burocráticas consolidadas. 


\section{Estado e desenvolvimento no Brasil}

Ao comparar as capacidades estatais entre Brasil e Argentina, Sikkink e Wolfson (1993) chamam atenção que a principal diferença reside na pouca capacidade estatal argentina para os processos de formulação de política econômica. No caso brasileiro, foi possível constituir uma burocracia relativamente autônoma em relação às pressões político-partidárias. Trata-se de uma herança da era Vargas. O Departamento Administrativo do Serviço Público (DASP) possuía uma burocracia com ingresso por concurso, estável e qualificada. Houve a formação de elites técnicas calcada na ideia de meritocracia. A burocracia insulada das pressões políticas e patrimonialistas mais diretas foi reforçada pelo governo de Juscelino Kubitschek (Sikkink et Wolfson, 1993). O Conselho de Desenvolvimento do governo de Juscelino foi constituído fundamentalmente por indivíduos procedentes do BNDE. O Plano de Metas foi formulado e posto em prática por instituições criadas na era Vargas.

No que diz respeito às políticas de desenvolvimento, Lafée (2005) observa uma maior estabilidade, uma maior diversidade de instrumentos e com maior alcance no caso brasileiro. As instituições chaves são essencialmente as mesmas que garantiram as estratégias do nacional-desenvolvimentismo. Notadamente, há destaque para o BNDES, o
CNPQ, a CAPES, as Superintendências de desenvolvimento regional ( a exemplo do SUDENE), o Fundo Nacional de Desenvolvimento Científico e Tecnológico (esse mais recente com início em 1969) e o Sistema S (SENAI, SENAR e SENAC). Este último data de meados dos anos 40 e, até hoje, figura como espinha dorsal do sistema vocacional de qualificação profissional abarcando os três principais setores da economia.

Um outro componente importante da rápida industrialização brasileira foi o grau de eficiência econômica das empresas estatais, em pese todas as críticas feitas durante as décadas de oitenta e noventa. Como lembra Trebat (1983), a principal realização da empresa pública estatal no Brasil foi a promoção de uma drástica transformação da estrutura econômica a partir dos anos 50. Tais empresas estiveram presentes em setores variados como aço, eletricidade, telecomunicações, petroquímica e mineração. Elas contribuíram para aumentar o nível de sofisticação técnica na economia, especialmente como clientes ou fornecedoras da indústria de bens capital privada.

No período mais recente a partir dos anos 90, pode-se acrescentar a continuidade políticas sociais (Bolsa Escola, SeguroDesemprego e o PRONAF) e políticas de estímulo ao desenvolvimento tecnológico (Fundos Setoriais) sem prejuízo das instituições fundamentais do período 
nacional-desenvolvimentista.

A partir do governo Lula, tal como nos governos de Néstor e Cristina Kirchner, há a retomada das políticas industriais e tecnológicas e uma preocupação do governo em desempenhar um papel ativo no upgrading industrial. Além das políticas industriais e de comércio exterior de 2003 e 2005, houve a criação da Agência Brasileira de Desenvolvimento Industrial vinculada ao Ministério do Desenvolvimento, Indústria e Comércio Exterior (MDIC) com a presença de representantes do BNDES, Banco do Brasil e Caixa Econômica Federal. A presença e ação dos bancos públicos para execução das políticas industriais é uma diferença institucional marcante entre o caso brasileiro e o caso argentino. Coutinho e colegas (2012) destacam algumas lições das políticas industriais brasileiras recentes: a) a prioridade política do mais alto nível de governo, b) o ativo envolvimento e comprometimento do Ministério da Fazenda, esse último mais recentemente com a entrada de um grupo alinhado com uma visão de desenvolvimento estratégico e a c) cooperação entre os diferentes órgãos do governo que possuem mandato para os instrumentos de política.

A maior proeminência das políticas industriais coincide com uma maior aproximação entre empresariado organizado e Estado em que as federações e associações empresariais revelam preocupação em estabelecer vínculos com os centros de poder
(Diniz, 2010). Isso é visto pelo governo como chave para recompor a aliança entre empresariado e governo. A participação empresarial associativa ao dos dois mandatos de Lula e do atual mandato de Dilma difere do discurso de independência em relação ao governo do período neoliberal. Neste sentido, merecem destaque os dois grandes espaços de concertação criados, o Conselho de Desenvolvimento Econômico e Social (CDES) e o Fórum Nacional do Trabalho (FNT).

No âmbito das políticas sociais, chama atenção que o patamar de gasto social público como percentual do PIB parte de um nível elevado, cerca de $18,8 \%$ do PIB. A distribuição deste gasto se divide em $11,8 \%$ para a seguridade social, 3,8\% para educação, 3\% para saúde e 1\% para habitação (Draibe, 2007). Em contraste com a Argentina, Draibe (2007) lembra que os programas sociais públicos no Brasil foram institucionalmente fortalecidos durante o período neoliberal. Isto corrobora o argumento deste trabalho em relação à importância da continuidade das políticas e instituições do Estado.

\section{Indicadores do desempenho das economias brasileira e argentina no contexto pós- neoliberal}

Os indicadores da última década revelam uma mudança de curso significativa para o caso argentino e uma mudança de caráter incremental para o caso brasileiro. 
Desde 2003, pode-se afirmar que existe uma tentativa de mudança no regime de acumulação $\quad$ argentino. $\quad$ Algumas características desta mudança são a expansão de políticas sociais, a progressiva eliminação do câmbio sobrevalorizado e a retomada de políticas industriais (Salama, 2012). Para Delgado e Ortiz (2006), o novo modelo de desenvolvimento argentino teve quatro fatores chaves:

Política Econômica heterodoxa: desvalorização do peso e expansão das políticas fiscais, especialmente com o aumento dos gastos sociais.

Recuperação da autoridade $e$ legitimidade política: reforma na corte suprema e retomada da confiança no governo e suas instituições.

Capacidade de mobilização da sociedade civil: organização dos trabalhadores e da sociedade civil para dar sustentação política à nova orientação política do governo.

Condições econômicas favoráveis: aumento dos preços das commodities e das exportações argentinas. Baixas taxas de juros em nível internacional e superávit fiscal de vários países latino-americanos.

Apesar do aumento na taxa de investimento, como pode ser visto pelo aumento da formação bruta de capital fixo (Figura 1), a estrutura de oferta não consegue acompanhar o aumento da demanda em função da perda estrutural de competitividade ocorrida na indústria argentina. De acordo com Salama (2012), o aumento do salário real entre 2003 e 2006 foi mais rápido do que o da produtividade do trabalho. $\mathrm{O}$ mesmo problema de descompasso entre aumento do salário real e aumento da produtividade do trabalho é visto no contexto brasileiro.

Conforme a Figura 1, percebe-se um aumento significativo da Formação Bruta de Capital Fixo como percentual do PIB para a Argentina, de 16\% em 2000 para 22\% em 2010. No caso brasileiro, a variação foi de $17 \%$ em 2000 para $18 \%$ em 2010. O coeficiente de variação para o Brasil foi de $6,6 \%$ e o da Argentina foi $22 \%$. A forte redução deste percentual com a crise de 2001 e a forte queda no PIB argentino contribuíram para essa variação maior. No entanto, há também o peso das políticas de incentivo industrial e das políticas sociais. 


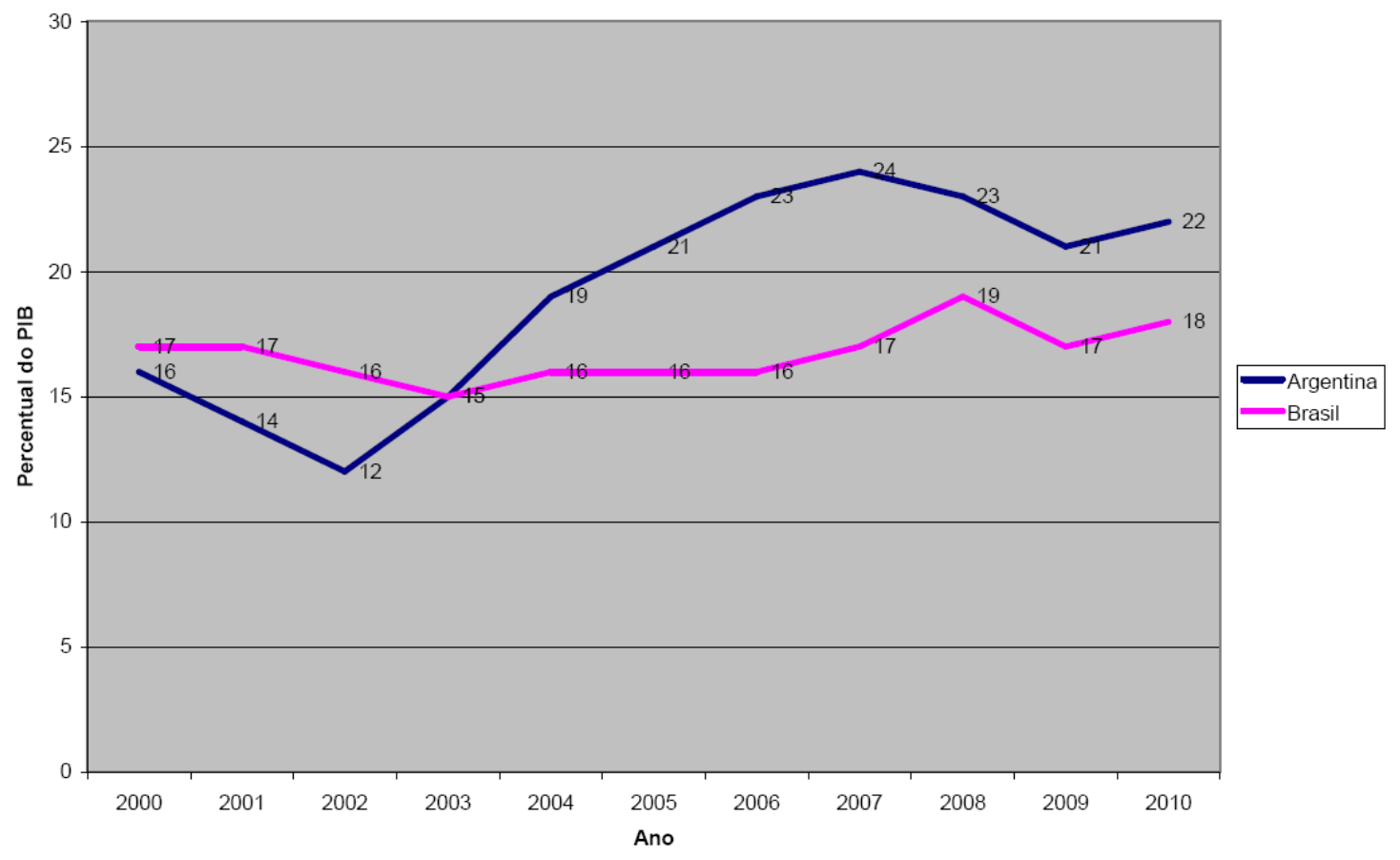

Figura 1 - Formação Bruta de Capital Fixo como \% do PIB (UNCTADSTAT)

Comparando com o caso brasileiro, a evolução do peso das exportações de produtos primários na pauta de exportações é menor na Argentina. No Brasil, tais produtos respondem por $23 \%$ em 2000 e chegam a 45\% em 2010 (Figura 2). Um aspecto diferenciador do caso brasileiro é o tamanho do mercado interno e a ênfase no consumo interno como vetor de crescimento econômico. Apesar disso, o aumento do peso das exportações de produtos primários é acompanhado de uma progressiva perda da capacidade industrial com sinais de desindustrialização. 


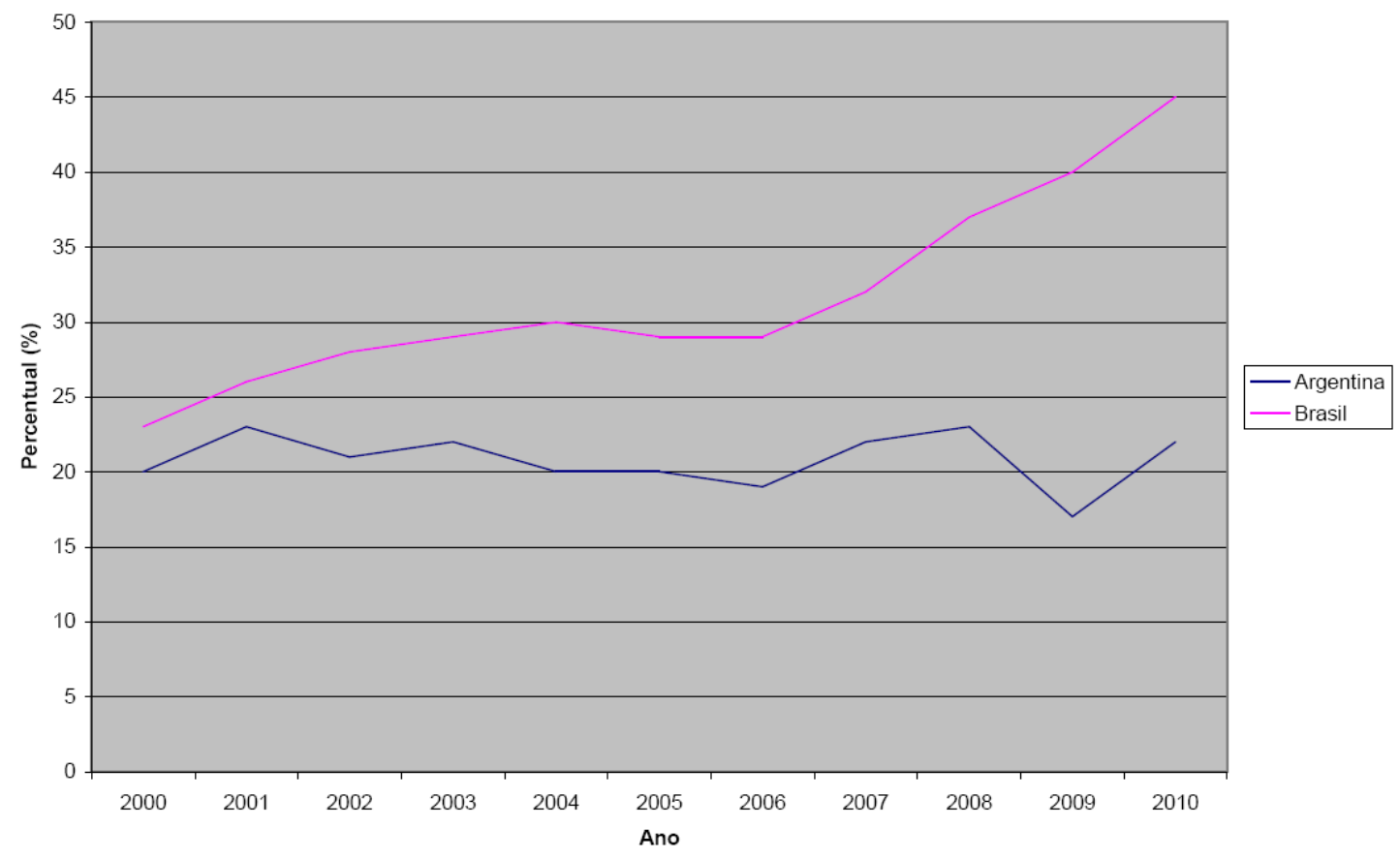

Figura 2 - Evolução da participação dos produtos primários na pauta de exportações 20002010 (UNCTADSTAT)

Como pode ser visto pela Figura 3, há uma correlação entre o aumento da participação das exportações de produtos primários e a diminuição da participação das exportações de manufatura. Isso sinaliza os efeitos deletérios da volatilidade dos preços das commodities sobre uma estratégia de desenvolvimento baseada em uma maior competitividade industrial, seguindo a lógica do upgrading industrial. No caso argentino, esta participação mantém-se relativamente estável para o mesmo período.

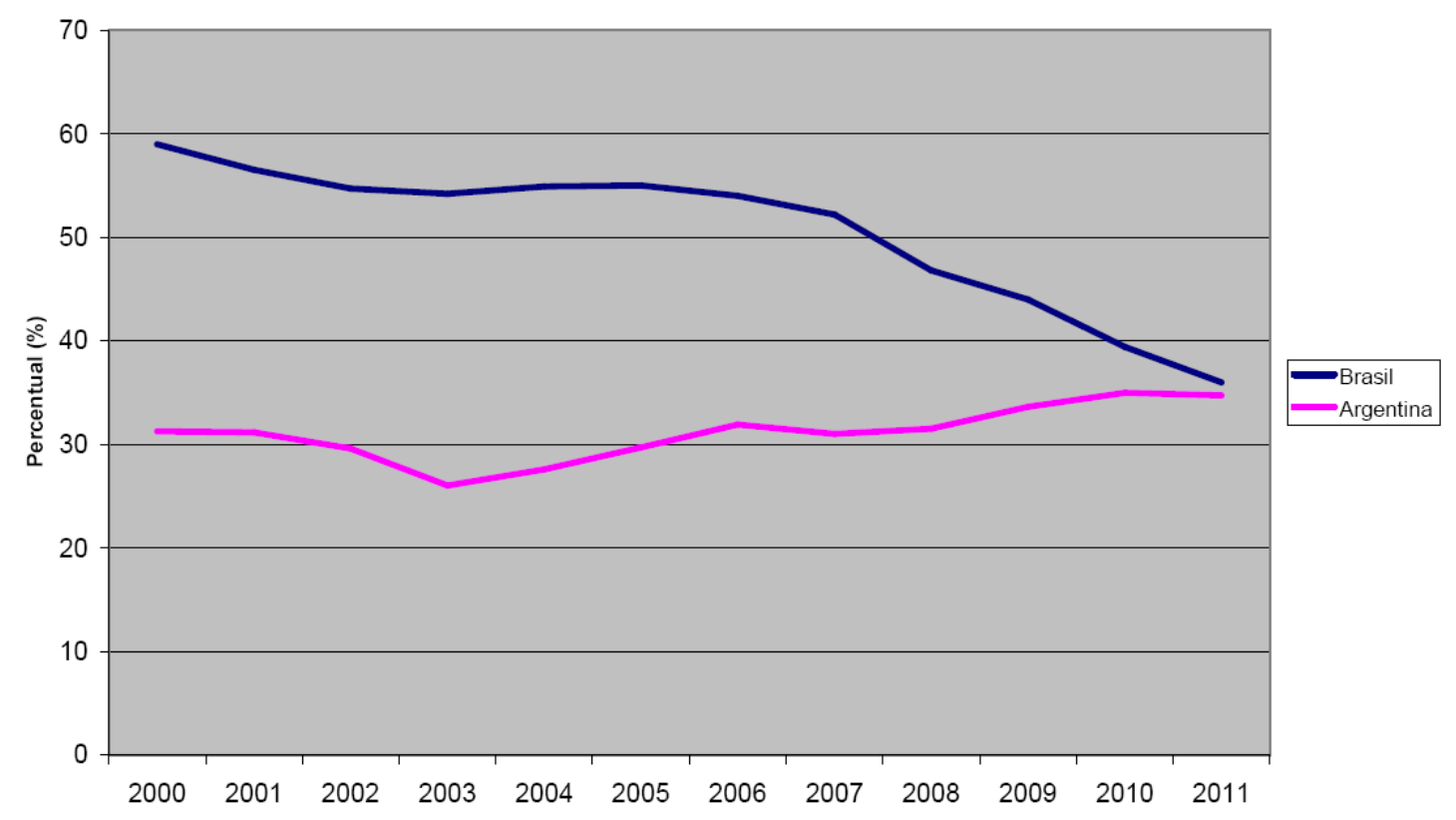


Figura 3 - Evolução da participação (\%) exportações de manufatura industrial nas exportações do Brasil e da Argentina 2000-2011 (UNCTADSTAT)

O Brasil é o país da América Latina com maiores investimentos em $\mathrm{P} \& \mathrm{D}$ como percentual do PIB, superando $1 \%$ nos últimos anos. É também o país com maior participação de empresas privadas nos investimentos em $P \& D$ na América Latina com cerca de $40 \%$ contra $26 \%$ de investimento privado da Argentina (CEPAL, 2008). Ainda que de forma tímida, ambos os países sinalizam uma melhora neste indicador de desenvolvimento tecnológico no período de 2000 a 2010 (Figura 4).

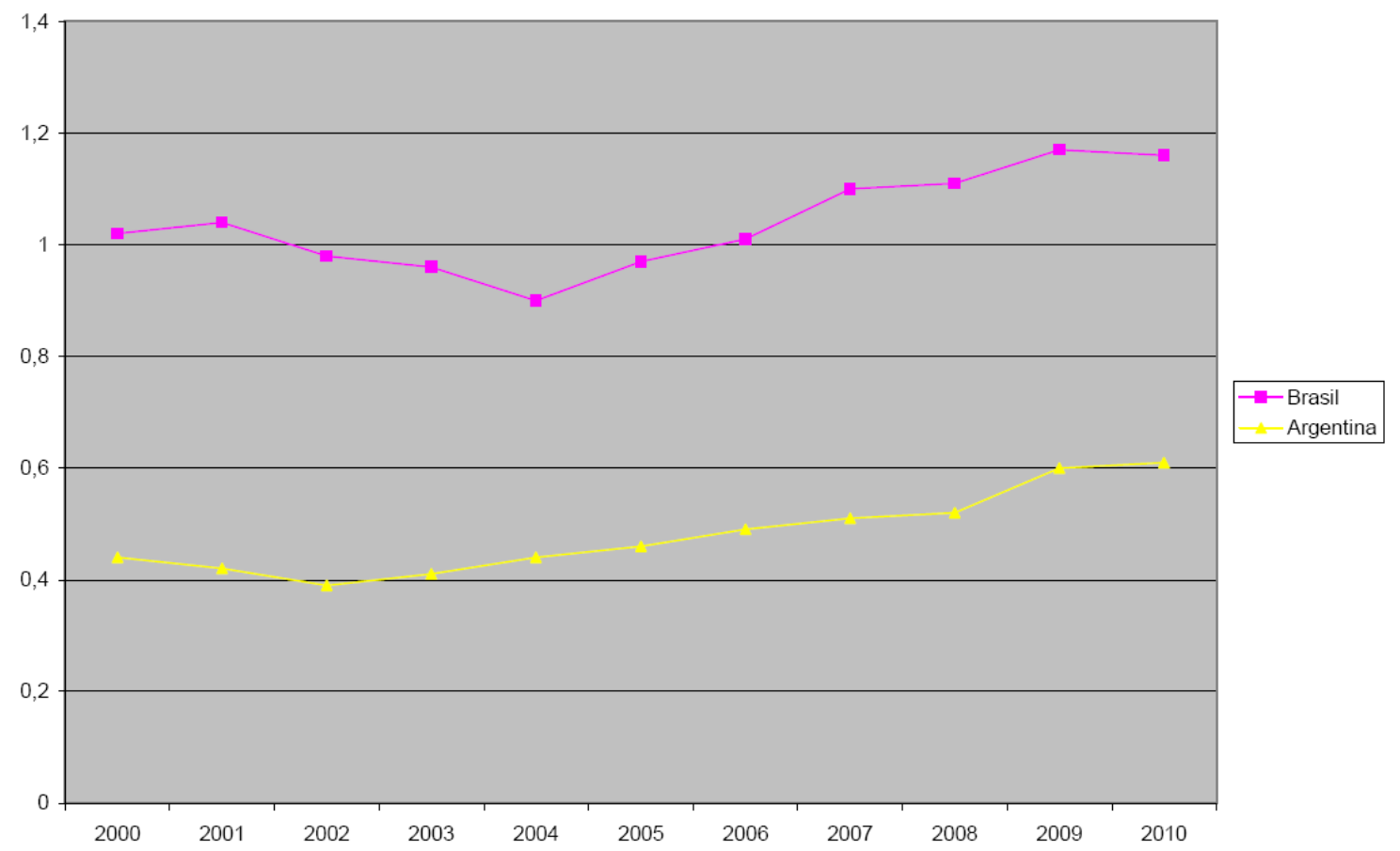

Figura 4 - Evolução da participação dos produtos primários na pauta de exportações 20002010 (MCT e MINCYT)

A evolução do gasto social argentino sinaliza uma variação maior do que no caso brasileiro. Isto é coerente com a maior intensidade do período neoliberal no caso argentino, além da descontinuidade das políticas sociais na Argentina em oposição a 
uma maior estabilidade para o caso brasileiro. Os dados corroboram as colocações de Draibe (2007) antes mencionadas. Um aspecto que chama atenção na Figura 5 são os pontos de inflexão na evolução dos gastos sociais entre
2007 e 2010. O período de crise internacional não arrefeceu as políticas sociais nos dois países, o que sinaliza uma consistência do Estado de bem-estar em desenvolvimento.

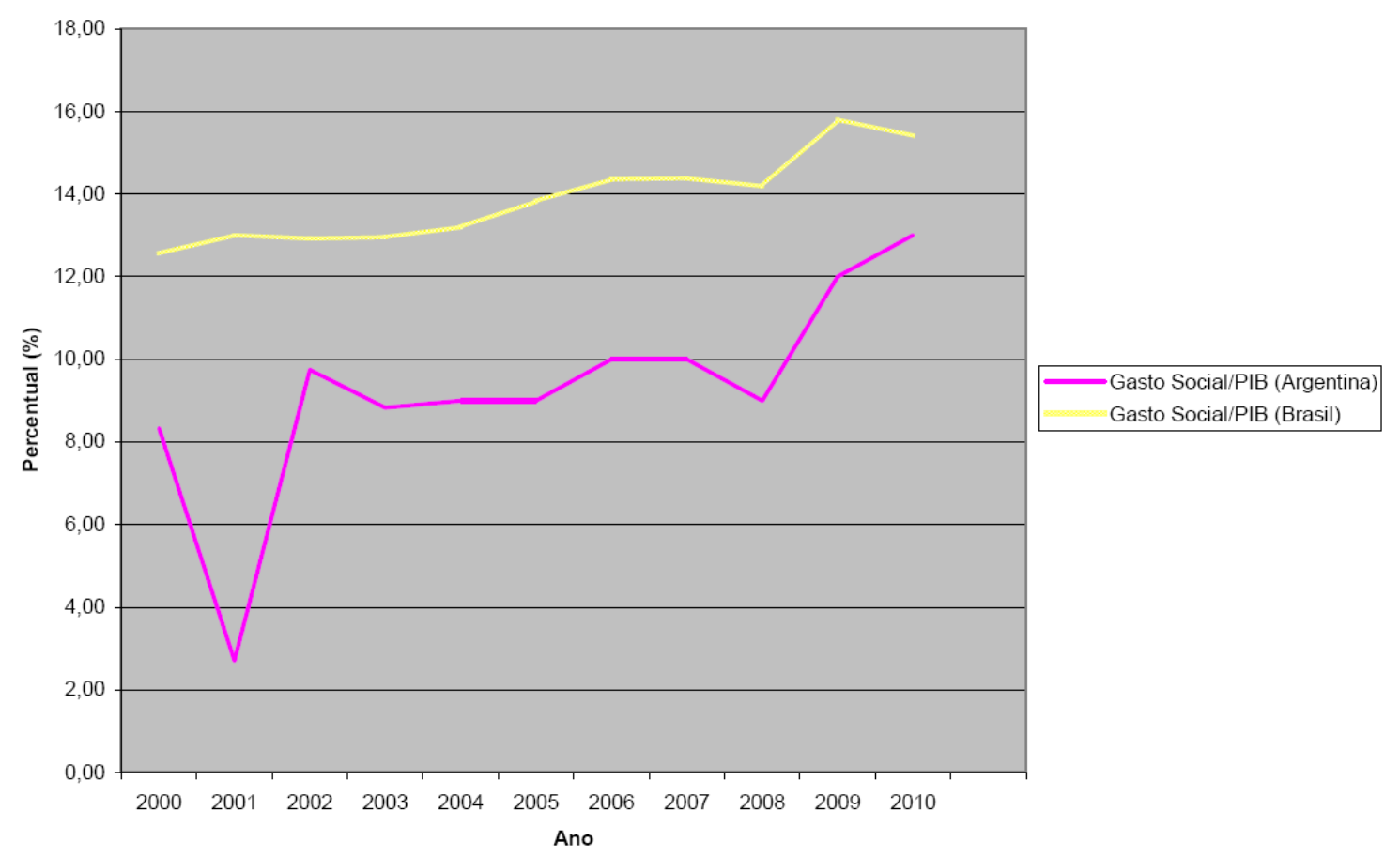

Figura 5 - Evolução dos gastos sociais como (\%) do PIB 2000-2010 (INDEC e IPEA)

Com exceção dos dados relativos à evolução da participação das exportações de manufatura, percebe-se uma maior estabilidade na evolução dos indicadores para a economia brasileira vis-à-vis o caso argentino. Ambos os países revelam uma melhora em seus indicadores em comparação ao período neoliberal. É necessário verificar a sustentação destas melhorias e se elas, de fato, abrem espaço para uma mudança institucional no capitalismo argentino e no capitalismo brasileiro, sinalizando as transformações produtivas defendidas pelo neoestruturalismo.

Olhando sob a perspectiva da retomada de um Estado desenvolvimentista em um contexto pós-neoliberal, é possível identificar maiores possibilidades no caso brasileiro em função da permanência de instituições chaves para os processos de desenvolvimento e do grau de capacidade estatal. O financiamento público para garantir as políticas industriais é um claro exemplo.

$\mathrm{Na}$ Argentina, o governo estabeleceu que alguns bancos privados deverão dispor de 
$5 \%$ de seus depósitos em pesos para o setor privado não financeiro, o correspondente a US\$ 3,3 bilhões ( $0,7 \%$ do PIB nacional). Tal linha de financiamento será destinada para a aquisição de bens de capital e construção de instalações para a produção de bens e serviços, sendo que metade da linha terá que ser concedida para pequenas e médias empresas (Valor Econômico, 07 de julho de 2012).

A medida sinaliza um esforço de aumentar os recursos financeiros para $o$ investimento produtivo. Apesar da sinalização positiva, são medidas muito limitadas diante da ausência de um financiamento público mais robusto.

\section{Considerações finais}

Como foi possível depreender a partir dos indicadores apresentados, os dois países se caracterizam por uma forte dependência em relação à exportação de commodities e de produtos agroindustriais para obtenção de excedentes na balança comercial. O contexto internacional de alta nos preços dos alimentos e commodities minerais propiciou uma situação mais confortável para as finanças públicas. Entretanto, a situação de dependência em relação às exportações de commodities aumenta a vulnerabilidade externa além de limitar uma divisão social do trabalho compatível com a criação de empregos mais qualificados, aumento de produtividade e taxas mais altas de inovação das firmas.

Como mostra a literatura, o desafio de construir um Estado desenvolvimentista requer a combinação de um Estado facilitador com uma estratégia de upgrading industrial acompanhada de aumento da inclusão social. Uma diferença relevante no caso brasileiro foi a permanência de instituições que foram construídas durante o período desenvolvimentista, com especial destaque para o BNDES. A contraparte argentina do BNDES, o Banco Nacional de Desarrollo (BANADE) foi criado em 1969, tardiamente em relação ao BNDES, e teve suas operações encerradas em 1993, auge do período neoliberal argentino. O BANADE tinha como objetivo o desenvolvimento de uma política audaciosa para as indústrias de base, grandes obras de infraestrutura e apoio integral para a indústria e mineração de capital nacional (Rougier, 2004).

Ao verificar a relação entre Estado e desenvolvimento nos dois países, foi possível identificar quatro diferenças fundamentais do Brasil em relação à Argentina; uma forte instituição financeira de desenvolvimento e instituições financeiras públicas, uma maior capacidade estatal com uma burocracia estável e meritocrática no caso brasileiro, políticas sociais de longo prazo e uma relação mais cooperativa entre Estado e empresariado.

Ao explorar as semelhanças e diferenças 
institucionais entre os Estados brasileiro e argentino, relacionadas com as políticas industriais e de inovação, é possível entender os limites e os fatores facilitadores das estratégias de desenvolvimento em construção.

Por serem países com desenvolvimento econômico muito semelhante, quando comparados com países capitalistas desenvolvidos, é mister entender, de maneira mais acurada as capacidades estatais e os padrões de relações entre empresariado, Estado e trabalhadores em conexão com as políticas de transformação produtiva. Afinal, reconhecer as diferenças é fundamental para que todos os gatos não sejam pardos quando se fala da economia política latinoamericana.

\section{Referências Bibliográficas}

Barbeito, Alberto C. and Goldberg, Laura Social Policy and Economic Regime in Argentina: Crisis and Retrenchment of Social Protection in Riesco, Manuel (org.) Latin America: a new developmental welfare state model in the making?, Hampshire, Palgrave Macmillan, 2007.

Chibber, V. Bureaucratic rationality and the developmental state in American Journal of Sociology, Vol. 107, Number 4, January 2002.

Delgado, Daniel G. et Ortiz, Ignacio C. Hacia un nuevo modelo de desarrollo, transformación y reproducción en el posneoliberalismo in Documentos y aportes en administración pública y gestión, Número 7, Santa Fe, Enero/Diciembre, 2006.

Diniz, Eli Democracy, State and Industry: continuity and change between the Cardoso and the Lula administrations in Latin American Perspectives, Vol. 38, December, 2010.

Dossi, Maria V. et Sanguinetti, Juan S. Intervención social del estado pos crisis del 2001. continuidades y rupturas con el modelo neoliberal in VIII Congreso Nacional de Ciencia Política de la Sociedad Argentina de Análisis Político". Universidad del Salvador. Buenos Aires. 6 al 9 de noviembre de 2007.

Draibe, Sonia The Brazilian Developmental Welfare State: Rise, Decline and Perspectives in Riesco, Manuel (org.) Latin America: a new developmental welfare state model in the making?, Hampshire, Palgrave Macmillan, 2007.

Ferrer, Aldo La economia argentina: desde las orígenes hasta princípios del siglo XXI, Cuarta Edición, Buenos Aires, Fondo de Cultura Econômica, 2008.

Grugel, Jean et Riggirozzi, Maria P. The Return of the State in Argentina in International Affairs, 83, p. 87-107, 2007.

Lafée, Daniel G. Política comercial e industrial y creación de empleo en Argentina y Brasil: un análisis Shift-Share aplicado al 
sector manufacturero" in XII Encuentro de Economía Pública, Palma de Mallorca, February 3-4, 2005.

Lange, Matthew and Rueschemeyer, Dietrich States and Development: historical antecedents of stagnation and advance, Hampshire, Palgrave Macmillan, 2005.

Leiva, Fernando Ignacio Latin American Neostructuralism: the contradictions of postneoliberal development, Minneapolis, University of Minnesota Press, 2008.

Madoery, Oscar Más y major trabajo para todos, Del Programa Jefes de Hogar al Programa Jóvenes. Politicas Activas de Empleo. Argentina 2003-2010, Buenos Aires, Oficina de país de la OIT para la Argentina, 2011.

Nicola, Philips The Southern Cone Model: the political economy of regional capitalist development in Latin America, London, Routledge, 2004.

Portes, A. e Smith, L. D. Institutions and national development in Latin America: a comparative study in Socio-Economic Review, Vol. 8, 585-621, 2010.

Riain, Sean O. The politics of High-Tech Growth: Developmental Network States in the Global Economy, Cambridge, Cambridge University Press, 2004.

Rougier, Marcelo Estado, empresas y crédito en la Argentina: Los orígines del Banco Nacional de Desarrollo in Desarrollo Económico, Vol. 43, No. 172, Jan. - Mar., pp. 515-544, 2004.

Rauch, James E. et Evans, Peter Bureaucracy and Growth: A Cross-National Analysis of the Effects of "Weberian" StateStructures on Economic Growth in American Sociological Review, Vol. 64, No. 5, pp. 748-765, 1999.

Salama, Pierre Crescimento e inflação na Argentina nos governos Kirchner in Estudos Avançados, 26 (75), 2012.

Schneider, Ben R. Business Politics and the State in the Twentieth Century Latin America, Cambridge, Cambridge University Press, 2004.

Schneider, Ben R. in Doner, Richard F. Explaining Institutional Innovation: Case Studies from Latin America and East Asia, New York, Social Science Research Council, 2010.

Segura-Ubiergo, Alex The Political Economy of the Welfare State in Latin: globalization, democracy and development, Cambridge, Cambridge University Press, 2007.

Trebat, Thomas J. Brazil's Stateowned Enterprises: a case study of the state as Enprepreneur, Cambridge, Cambridge University Press, 1983. 